\title{
Comparison Between Commercial and Aquatic Lily Lignins
}

\author{
M.E. Mendoza-Duarte ${ }^{1}$, J.L. Espinoza-Acosta ${ }^{1}$, C. Leyva-Porras ${ }^{1}$, I.A. Estrada-Moreno ${ }^{2}$ \\ 1. Ingeniería y Química de Materiales, Centro de Investigación en Materiales Avanzados, S.C. (CIMAV) \\ Chihuahua, México. \\ 2. CONACyT - Centro de Investigación en Materiales Avanzados, S.C., Chihuahua, México. \\ * Corresponding author: ivan.estrada@cimav.edu.mx
}

Lignocellulosic biomass is widely known for its potential use to produce chemicals and biomaterials, also, is the second most abundant natural biopolymer in the world after cellulose [1]. Its structure and physical and chemical behavior depend on the raw material, growing conditions of the plant and extraction methods used [2]. Aquatic lily can act as a source of lignin as it is an abundant plant that grows in water channels and lakes. The Lily Lignin (LL) was obtained by dissolution in alkaline media of fibers from aquatic lily, and it is compared with commercial Kraft Lignin (KL).

Figure 1a shows infrared spectra of lignins; both lignins presents bands related to the presence of $\mathrm{O}-\mathrm{H}$ stretching vibrations in aromatic and aliphatic O-H groups, $3410 \mathrm{~cm}^{-1}$ in $\mathrm{KL}$ and $3300 \mathrm{~cm}^{-1}$ in LL. The signals located in 2960-2835 $\mathrm{cm}^{-1}$ correspond to $\mathrm{C}-\mathrm{H}$ vibrations [3], being more evident in the LL. Bands occurring between 1600 and $1500 \mathrm{~cm}^{-1}$ are characteristics of aromatic compounds (phenolic hydroxyl groups) and are attributed to aromatic skeleton vibrations. The band related to the phenolic groups, $1375 \mathrm{~cm}^{-1}$ is more evident in the LL, because to greater hydrolysis of methoxy groups and the ether linkage between lignin polymer in the case of the LL than in KL. Finally, the signal around 1630 $\mathrm{cm}^{-1}$ in $\mathrm{LL}$ is a characteristic absorption of conjugated carbonyl group $\mathrm{C}=\mathrm{O}$ of lignin.

The thermogravimetric (TG) curves obtained for each lignin are shown in Figure 1b, it can be observed that at a temperature lower than $200{ }^{\circ} \mathrm{C}$, LL has greater thermal stability than KL. The initial degradation temperature considered at $5 \%$ of weight loss $\left(\mathrm{T}_{5} \%\right)$ for $\mathrm{LL}$ is around $196.19{ }^{\circ} \mathrm{C}$, whereas the decomposition temperature of the $\mathrm{KL}$ is around $104.91{ }^{\circ} \mathrm{C}$.

The SEM images, Figure $2 \mathrm{a}$ and $2 \mathrm{~b}$, shows the morphology of the lignins. As can be seen, the lignin from aquatic lily presents smaller particles that KL. This could be attributed to the obtaining method, which produces more damage in lignin. In the case of KL, it is obtained from a chemical solution (sodium hydroxide and sodium sulfide) at high temperatures $\left(170{ }^{\circ} \mathrm{C}\right)$ and pressures, presenting content of impurities of less than $2.30 \%$ of sugars and a different morphology [4].

In conclusion, we obtained lignin from aquatic lily, a plant that could be considered as a contaminant in some places. The infrared and thermogravimetric analysis shows similar results between a commercial Kraft Lignin and lily lignin, having as a mean difference the particle size. 


\section{References:}

[1] D Watkins, M Nuruddin, M Hosur, A Tcherbi-Narteh, and S Jeelani, Journal of Materials Research and Technology 4 (2015), p. 26.

[2] O Gordobil, R Delucis, I Egüéss, and J Labidi, Industrial Crops and Products 72 (2015), p. 46.

[3] L Klapiszewski, M Nowacka, G Milczarek, and T Jesionowski, Carbohydrate Polymers 94 (2013), p. 345.

[4] M Sifontes, and M Domine, Avances En Ciencias E Ingeniería, 4 (2013), p. 15.

[5] The authors thank Karla Campos, Daniel Lardizabal and Luis de la Torre for their helpful assistance.

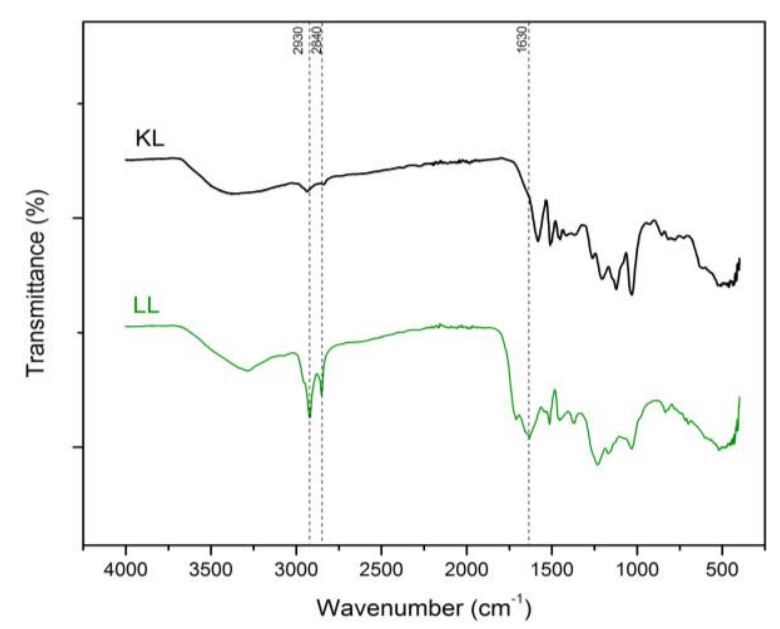

(a)

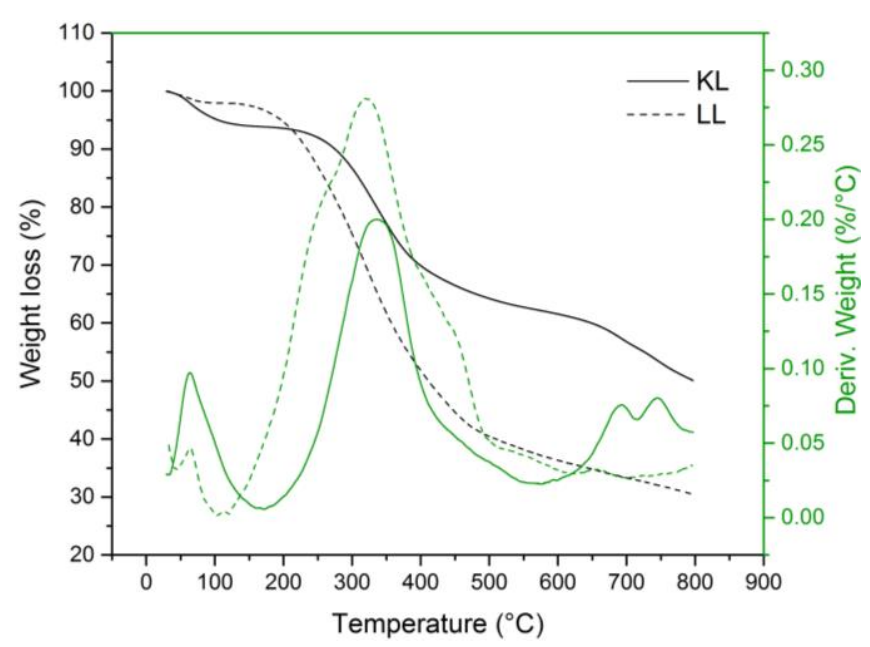

(b)

Figure 1. Fourier transform infrared spectra of lignins (a) and thermograms of lignin powders (b).

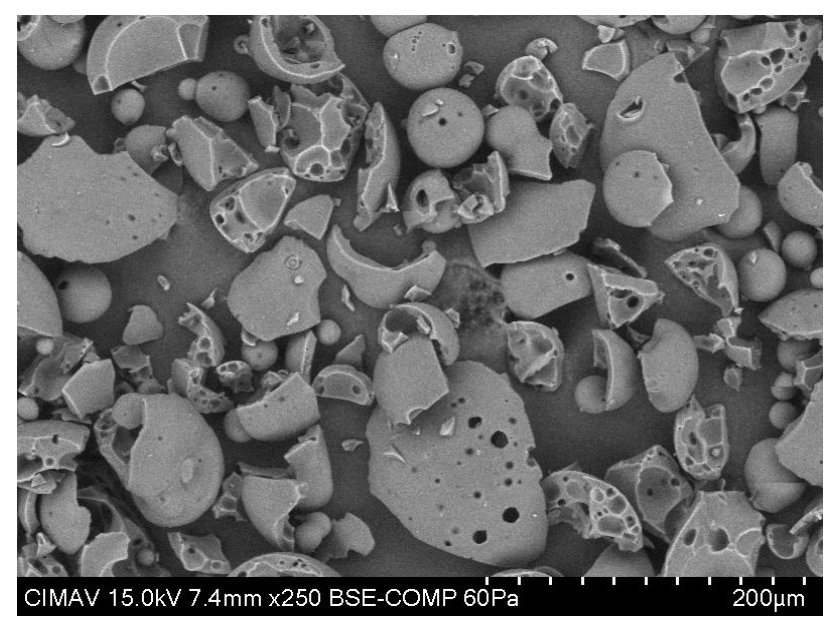

(a)

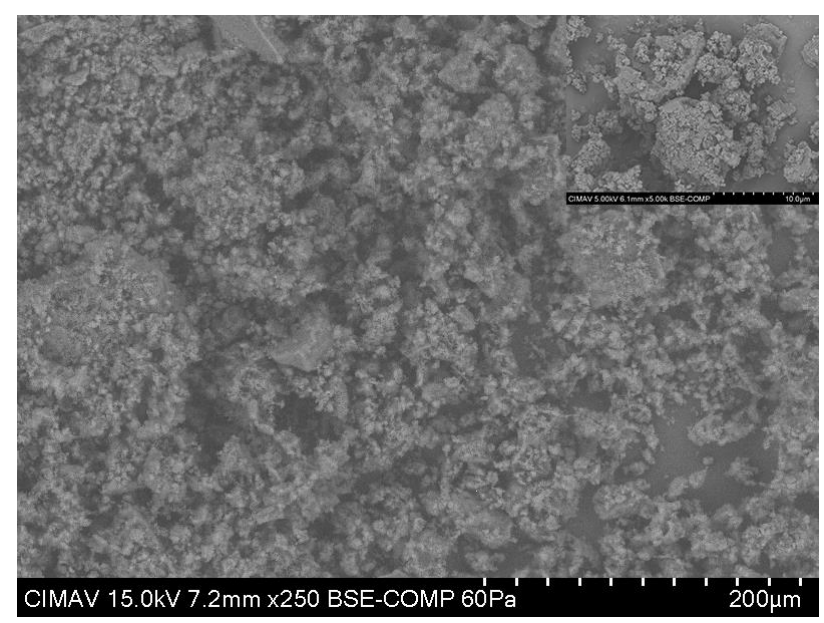

(b)

Figure 2. SEM micrographs of Kraft Lignin (a) and Lily Lignin (b), the inset has greater amplification. 